\title{
VARIACIÓN EN GRADOS DE LATENCIA EN SEMILLAS ENTRE COLECTAS DE CHILE PIQUÍN (CAPSICUM ANNUUM VAR. GLABRIUSCULUM)
}

\author{
Anaid Cano-Vázquez ${ }^{1}$, Ma. Cristina López-Peralta ${ }^{1}$, Hilda A. Zavaleta-Mancera ${ }^{2}$, \\ Nicacio Cruz-Huerta ${ }^{1}$, Iván Ramírez-Ramírez ${ }^{1}$, Alfonso Gardea-Béjar ${ }^{3}$ Y \\ Víctor A. GonZÁleZ-Hernández ${ }^{1,4}$ \\ ${ }^{1}$ Postgrado en Recursos Genéticos y Productividad-Fisiología Vegetal, Colegio de Postgraduados, \\ Campus Montecillo, Texcoco, Estado de México, México \\ ${ }_{2}^{2}$ Postgrado en Botánica, Colegio de Postgraduados, Campus Montecillo, Texcoco, Estado de México, México \\ ${ }^{3}$ Centro de Investigación en Alimentación y Desarrollo, A.C. Hermosillo, Sonora, México \\ ${ }^{4}$ Autor para correspondencia: vagh@colpos.mx
}

\begin{abstract}
Resumen: El chile piquín (Capsicum annuum var. glabriusculum) que se consume en México es, en su mayoría, recolectado de plantas silvestres. Esta actividad podría amenazar la diversidad genética de la especie. Idealmente, el chile piquín debería producirse intensivamente para proteger la población silvestre y satisfacer la demanda; sin embargo, la baja germinación de semillas de esta especie de chile ha sido tradicionalmente un problema para su establecimiento a nivel comercial. Las causas de lo anterior son desconocidas. Identificar las causas de la baja germinación y la diversidad entre colectas es, por tanto, de importancia. Se evaluaron 16 diferentes colectas de chile piquín provenientes de siete estados del país y del sur de Estados Unidos. Un estudio morfológico determinó que en las colectas evaluadas no existen diferencias ni barreras morfológicas que impidan la germinación apropiada de las semillas. Una cinética de imbibición determinó que no existen impedimentos físicos para el paso apropiado de agua al interior de las semillas; sin embargo, la germinación de las 16 colectas fue muy variable ( 0 a $66 \%)$, con un promedio de $15 \%$. El pretratamiento de las semillas con la hormona $\mathrm{AG}_{3}(5,000 \mathrm{ppm})$, elevó la tasa promedio de germinación a $59 \%$ en 14 de las 16 colectas, mientras que los tratamientos de acondicionamiento con peróxido de hidrógeno y nitrato de potasio solamente mejoraron la germinación de semillas en dos y cuatro colectas, respectivamente. El presente trabajo corrobora que la limitante de germinación en semillas de chile piquín se debe a un fenómeno de latencia fisiológica, la cual puede romperse con aplicación exógena de $\mathrm{AG}_{3}$ a 5,000 ppm, cuyos efectos varían entre colectas.
\end{abstract}

Palabras clave: ácido giberélico, germinación, imbibición, latencia.

Abstract: Chile piquin (Capsicum annuum cv. glabriusculum) consumed in México is usually harvested from wild grown plants. This activity might threaten the genetic diversity in this species. However, chile piquin germination has traditionally been difficult for intensive greenhouse sowing. The causes for such behavior are unknown. Accessions from seven production zones in the country and Southern USA were collected, and studied. Morphological studies determined there are no significant morphological differences or barriers among accessions that might prevent seed germination. An imbibition kinetic study showed no limitations for water penetration into seed tissues. Yet the seed germination rate varied among the 16 accessions (0 to 66\%) with an average of $15 \%$. Seed conditioning with $\mathrm{AG}_{3}$ at $5,000 \mathrm{ppm}$ increased mean germination rate to $59 \%$ in 14 out of 16 accessions. Hydrogen peroxide and potassium nitrate did not increase germination rates of viable seeds, except on two and four accessions, respectively. This work corroborates that chile piquin seed germination is restricted by physiological dormancy that giberellic acid pre-conditioning can overcome with varying degrees among accessions.

Key words: dormancy, germination, gibberellic acid, imbibition.

$\mathbf{E}^{1}$ fruto de chile piquín (Capsicum annuum var. glabriusculum) es un condimento de alto consumo en México. Este chile se encuentra distribuido en forma silvestre a lo largo de la República Mexicana y en el sur de los Estados
Unidos de América, lo que muestra una amplia adaptabilidad ambiental, probablemente asociada con su diversidad genética. Dada la naturaleza predominantemente silvestre de esta especie, su fruto generalmente se obtiene por reco- 
lección en poblaciones silvestres y no de plantaciones comerciales, lo que podría amenazar su diversidad genética. Algunos esfuerzos aislados por promover la siembra de esta especie para obtener mejores rendimientos y calidad de fruto se han realizado, pero la baja tasa de germinación de sus semillas (Hernández-Verdugo et al., 2010; Medina-Martínez et al., 2002; Medina-Martínez et al., 2010) ha dificultado su domesticación.

La tasa de germinación y el establecimiento de la plántula en el campo son indicadores de desempeño agronómico. En el campo hay numerosas variables ambientales que influyen directamente sobre la germinación, y es frecuente que las condiciones naturales sean poco favorables para este proceso. Se han reportado bajas tasas de germinación en semillas de chile piquín, lo que se le ha atribuido a la impermeabilidad y dureza de la cubierta seminal, a la baja permeabilidad del endospermo y a una latencia profunda del embrión (Bañuelos et al., 2008; Araiza et al., 2011), aún en condiciones que favorecen la germinación de semillas ortodoxas. Para mejorar la germinación, en otras especies y géneros se han utilizado tratamientos químicos, debido a las ventajas que ofrecen, como facilidad y costos relativamente bajos de aplicación, inclusive en lotes grandes de semilla (Shim et al., 2008).

Los tratamientos químicos de acondicionamiento metabólico más utilizados en semillas de especies hortícolas se hacen con los compuestos: peróxido de hidrógeno $\left(\mathrm{H}_{2} \mathrm{O}_{2}\right.$; Flores et al., 2008), nitrato de potasio $\left(\mathrm{KNO}_{3}\right.$; Jarma et al., 2007; Marín et al., 2007; Andrade-Rodríguez, 2008) y ácido giberélico $\left(\mathrm{AG}_{3}\right.$; Magnitskiy y Ligarreto, 2007; García et al., 2010; Araiza et al., 2011). Mediante inmersión de semillas en una solución acuosa de $\mathrm{AG}_{3}$, a 5,000 ppm por 24 h, Ramírez (2008) logró incrementar de 8 a $82 \%$ la germinación de dos poblaciones silvestres de chile piquín provenientes del centro de Tamaulipas.

Los mecanismos de acción de cada tratamiento de acondicionamiento de semillas no se conocen en detalle; sin embargo, se han postulado algunas teorías. Por ejemplo, Ogawa e Iwabuchi (2001) propusieron que la degradación del $\mathrm{H}_{2} \mathrm{O}_{2}$ activa mecanismos de recolección de moléculas de oxígeno que pueden ser utilizadas para la respiración mitocondrial. Por su parte, Shim et al. (2008) sugirieron que el $\mathrm{KNO}_{3}$ promueve la reparación metabólica de tejidos y el aumento de respiración, con lo cual se mejora la tasa de crecimiento y la germinación. Según Chen y Bradford (2000), el $\mathrm{AG}_{3}$ es una fitohormona que activa proteínas que degradan el endospermo de la semilla, lo que permite la movilización de reservas del endospermo al embrión. De acuerdo con Richards et al. (2001), el $\mathrm{AG}_{3}$ actúa directamente sobre genes que limitan la germinación.

Los tratamientos de acondicionamiento metabólico no son universales para todas las especies, por lo que pueden funcionar para algunas especies de un género, pero no necesariamente funciona para todas. Por tal motivo, esta investigación comparó diversas colectas de chile piquín en cuanto a capacidad germinativa de las semillas, de tal forma que se determinará si la escasa germinación de las semillas de chile piquín se debe a una restricción morfológica que limite la absorción de agua durante la imbibición (latencia física), o se debe a algún tipo de latencia fisiológica que pueda ser rota mediante tratamientos de pre-acondicionamiento.

\section{Materiales y métodos}

Colectas de chile piquín. Los 16 materiales conseguidos para esta investigación (Cuadro 1) fueron obtenidos como frutos secos o semillas, por dos vías: mediante recolección

Cuadro 1. Relación de las colectas utilizadas para el estudio de germinación de chile piquín.

\begin{tabular}{|c|c|c|c|}
\hline Lugar de colecta & Donante & Institución & Material \\
\hline 1. Tucson, Arizona, E.U.A. (M1) & Dr. Alfonso Gardea & CIAD & Fruto seco \\
\hline 2. Tucson, Arizona, E.U.A. (M2) & Dr. Alfonso Gardea & CIAD & Fruto seco \\
\hline 3. Huepac, Sonora $(\mathrm{H})$ & Dr. Alfonso Gardea & CIAD & Fruto seco \\
\hline 4. La Montosa Moctezuma, Sonora (MM) & Dr. Alfonso Gardea & CIAD & Fruto seco \\
\hline 5. La Montosa, Sonora (LM) & Dr. Alfonso Gardea & CIAD & Fruto seco \\
\hline 6. Babiácora, Sonora & Dr. Alfonso Gardea & CIAD & Fruto seco \\
\hline 7. Badiraguato, Sinaloa & Dr. Víctor H. Aguilar & COLPOS & Semilla \\
\hline 8. Acaponeta, Nayarit & Dr. Víctor H. Aguilar & COLPOS & Semilla \\
\hline 9. Tepic, Nayarit & Dr. Víctor H. Aguilar & COLPOS & Semilla \\
\hline 10. Tomatlán, Jalisco & Dr. Víctor H. Aguilar & COLPOS & Semilla \\
\hline 11. San Carlos, Tamaulipas & M.C. Moisés Ramírez & INIFAP & Semilla \\
\hline 12. Soto La Marina, Tamaulipas & M.C. Moisés Ramírez & INIFAP & Semilla \\
\hline 13. Tuxpan, Veracruz* & Dr. Nicacio Cruz H. & COLPOS & Fruto seco \\
\hline 14. Xicotepec, Puebla* & Dr. Víctor A. González & COLPOS & Fruto seco \\
\hline 15. Cuetzalan, Puebla* & M.C. Edgardo Bautista & COLPOS & Fruto seco \\
\hline 16. Sierra Sonora, Sonora* & Dr. Víctor A. González & COLPOS & Fruto seco \\
\hline
\end{tabular}

* Frutos secos adquiridos en mercados locales. 
directa en los sitios donde crecen las plantas por investigadores interesados en la especie, la mayoría de los cuales son miembros de la Red de Chile de SINAREFI-SAGARPA; y mediante compra en mercados locales. Las 16 colectas provienen de siete estados del país (Sonora, 4 colectas; Sinaloa, 1; Puebla, 2; Tamaulipas, 3; Jalisco, 1; Nayarit, 2; y Veracruz, 1), más dos colectas de Arizona, E.U.A. Las colectas se hicieron en los años 2011 y 2012, y una vez recibidas en el laboratorio se conservaron en refrigeración a $4{ }^{\circ} \mathrm{C}$. De los frutos se extrajeron las semillas y se descartaron las semillas vanas mediante un diafanoscopio. Los ensayos efectuados se llevaron a cabo durante el 2012 y el 2013.

Variables morfológicas. Se usaron lotes de semillas de chile piquín de diez colectas representativas de tres grupos de germinación (alta, mediana y baja), establecidos en ensayos previos efectuados sin aplicación de promotores del proceso (Cano-Vázquez, 2013). Las diez colectas fueron: Acaponeta, Arizona M2, Babiácora, Badiraguato, Cuetzalan, La Montosa Moctezuma, Soto La Marina, Tepic, Tomatlán y Tuxpan. De cada colecta, 12 semillas se fijaron a un portaobjetos con un adhesivo de cianoacrilato (Kola Loka ${ }^{\circledR}$ ). Una vez seco el adhesivo, la semilla se desgastó con lija de agua número 400 hasta exponer el embrión y el endospermo, de acuerdo con lo propuesto por Guerrero-Muñoz et al. (2006). Posteriormente se colocó una gota de ácido per-yódico en la parte lijada de cada semilla, dejando reposar por $15 \mathrm{~min}$. El ácido fue removido mediante tres enjuagues con agua destilada. Enseguida, se colocó una gota de reactivo de Schiff sobre cada semilla y se dejó por 10 min o hasta observar el contraste entre el embrión y el endospermo, e inmediatamente después se enjuagó con agua destilada y se procedió a la observación en estereoscopio.

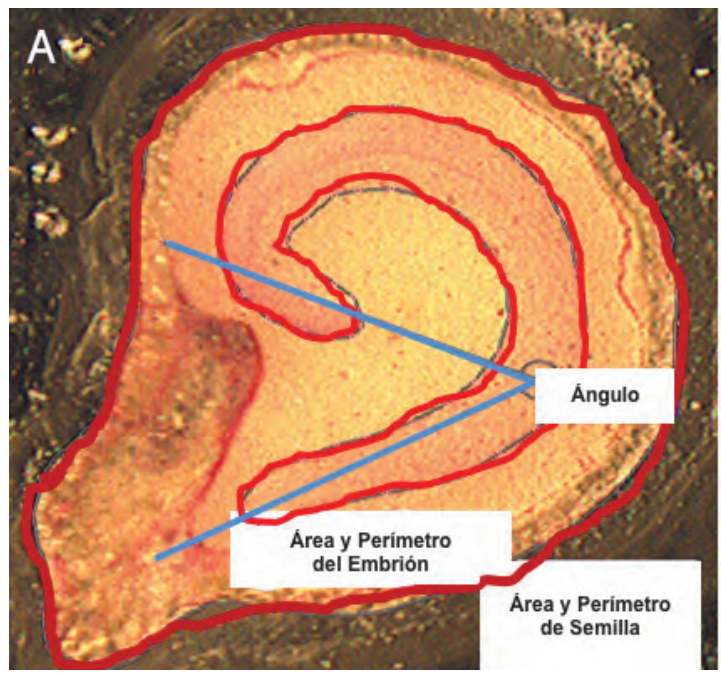

Las semillas teñidas se fotografiaron y las imágenes se procesaron con el programa Motic Images Plus 2.0 (Motic Asia; Hong Kong). En cada semilla se determinó área $\left(\mathrm{mm}^{2}\right)$ y perímetro $(\mathrm{mm})$ de la semilla completa, así como área y perímetro del embrión, ángulo de curvatura de los cotiledones con respecto al eje embrionario, longitudes (mm) del eje mayor y del eje menor, grosor de la cubierta seminal (mm) y longitud ( $\mathrm{mm}$ ) del eje hipocótilo-radícula. Además se calcularon los cocientes: área de la semilla entre área del embrión, área del embrión entre área de la semilla, diámetro Ferret $\mathrm{DF}=\sqrt{ }(4$ área $\left.) \pi^{-1}\right)$, índice de redondez $\mathrm{IR}=(4 \cdot \pi \cdot$ área $)\left(\text { perímetro }^{2}\right)^{-1}$, e índice de alargamiento IE $=$ longitud del eje mayor (longitud del eje menor) ${ }^{-1}$; como lo indican Guerrero-Muñoz et al. (2006), López-Santiago et al. (2008) y Núñez-Colín et al. (2011). La figura 1 ilustra las variables medidas.

Cinética de imbibición y distribución de biomasa durante la germinación. Para ambas cinéticas se seleccionaron 288 semillas no vanas de la colecta Tuxpan, por haber sido la de mayor germinación natural entre las 16 colectas previamente evaluadas. Las semillas se germinaron en 96 cajas Petri con fondo de toalla de papel humedecido con $25 \mathrm{~mL}$ de agua destilada. Las cajas y las toallas de papel fueron desinfectadas previamente con una solución de hipoclorito de sodio a $3 \%$ de producto comercial $\left(\right.$ Cloralex $^{\circledR}$ ), durante 15 min. Las semillas fueron previamente lavadas con detergente y desinfectadas con el fungicida Benlate ${ }^{\circledR} 0.4 \%$ por 15 min, más una solución de Microdyn ${ }^{\circledR} 0.05 \%$ por 30 min. Después de la siembra, las cajas Petri se sellaron con película plástica y se colocaron en una incubadora Thelco (Flexible Scientific; E.U.A.) a $30{ }^{\circ} \mathrm{C}$ y oscuridad.

Durante la germinación se tomaron muestras de 12 semi-

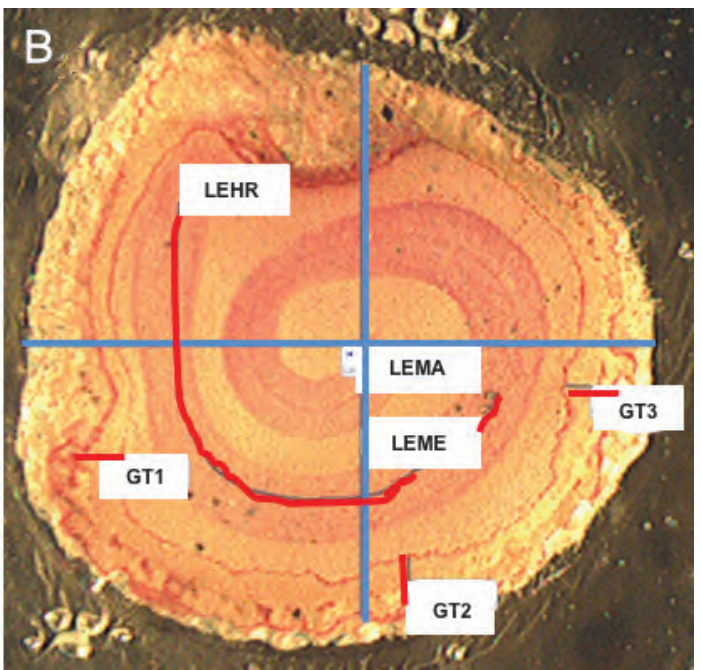

Figura 1. Semillas de chile piquín lijadas en el plano medio para mostrar los índices morfológicos evaluados. A) En la colecta Acaponeta, se ilustra el área y perímetro, de semilla y de embrión, y el ángulo de curvatura del embrión; B) En la colecta Tomatlán, se ilustra la longitud del eje hipocótilo-radicular (LEHR), grosor en tres puntos de la cubierta seminal (GT1, GT2 y GT3), longitud del eje mayor (LEMA) y longitud del eje menor (LEME). 


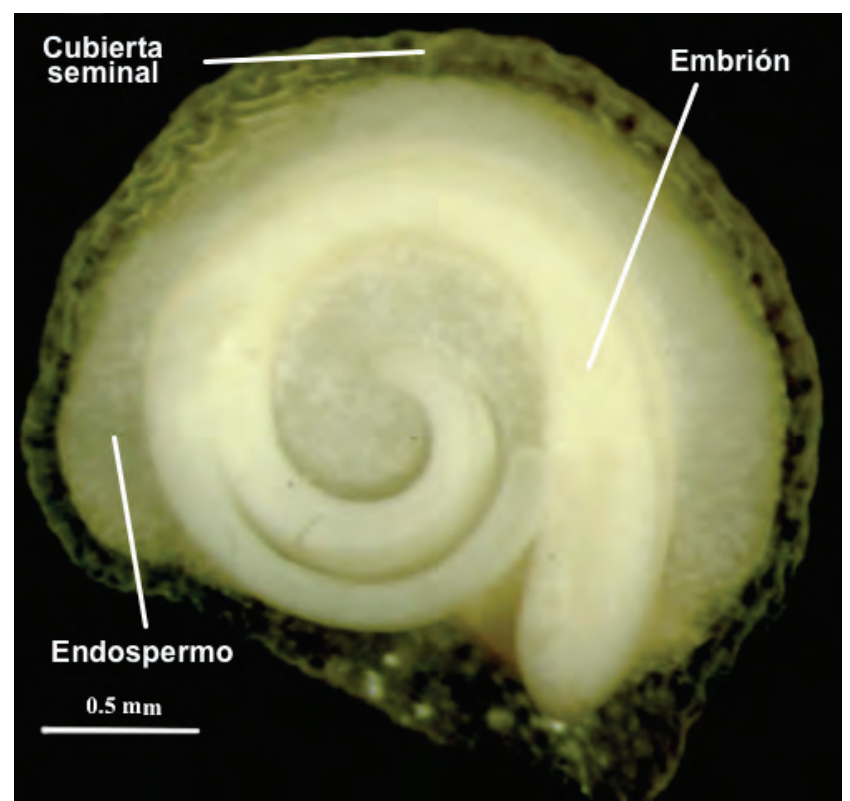

Figura 2. Estructuras de la semilla de chile piquín.

llas (tres repeticiones de cuatro semillas), a las $0,8,16$ y 24 h después de la siembra, y después cada 24 h por 21 días. Cada semilla muestreada se disecó por el plano medio con ayuda de un estereoscopio Stereo Star AO570 (American Optical, E.U.A.), y de ella se aislaron la cubierta seminal, el endospermo y el embrión (Figura 2). Por su diminuto tamaño, las estructuras de las cuatro semillas de una repetición se tuvieron que juntar $(n=3)$ para ser pesadas en balanza analítica Sartorius H51 (Sartorius; Alemania), y así poder registrar el peso fresco de cada muestra. Después se secaron en una estufa a $65^{\circ} \mathrm{C}$ por $48 \mathrm{~h}$ y se registró el peso seco con la misma balanza analítica.

La cinética de imbibición de cada parte de la semilla se construyó con sus respectivos porcentajes de humedad $\left.\{[(\text { peso fresco-peso seco }) \times 100] \text { (peso fresco })^{-1}\right\}$. La cinética de distribución de biomasa entre las partes de la semilla se hizo con los datos de peso seco de las mismas muestras.

Evaluación de promotores de germinación. En este ensayo se evaluaron semillas no vanas de las 16 colectas de chile piquín enlistadas en el cuadro 1. Las semillas fueron lavadas con detergente y desinfectadas con Benlate ${ }^{\circledR} 0.4 \%$ por 15 min, más una solución de Microdyn ${ }^{\circledR} 0.05 \%$ por 30 min.

Las semillas se sometieron a tres tratamientos de acondicionamiento por inmersión durante $24 \mathrm{~h}$ : ácido giberélico $\mathrm{AG}_{3}$ a $5 \mathrm{~g} \mathrm{~L}^{-1}$ (Flores et al., 2008), $\mathrm{H}_{2} \mathrm{O}_{2} 3 \%$ (Marín et al., 2007) y $\mathrm{KNO}_{3}$ a una concentración equivalente a -1.2 $\mathrm{MPa}$ (Medina et al., 2010), más un testigo sin acondicionamiento previo. Las semillas tratadas se secaron durante $72 \mathrm{~h}$ por exposición al aire en condiciones ambientales de laboratorio, para ser comparadas con las semillas secas no remojadas del tratamiento testigo.

Para la germinación, las semillas se colocaron en cajas Petri con fondo de toalla de papel humedecido con agua destilada. Las cajas y las toallas de papel se desinfectaron previamente con una solución de hipoclorito de sodio a $3 \%$ por 15 min. Para disminuir el riesgo de contaminación por microorganismos se aplicó una solución de $\operatorname{Captan}^{\circledR}$ a $5 \mathrm{~g} \mathrm{~L}^{-1}$, hasta saturar la toalla de papel. Las cajas Petri se sellaron

Cuadro 2. Promedios y desviaciones estándar de medidas morfológicas, curvatura del embrión, tres índices anatómicos de semillas y la relación entre las áreas del embrión y la semilla, en semillas de diez colectas de chile piquín agrupadas por capacidad de germinación. PS, perímetro de la semilla; AS, área de la semilla; PE, perímetro del embrión; AE, área del embrión; GCS, grosor de la cubierta seminal; LEHR, longitud del eje hipocótilo radicular; CE, curvatura del embrión; DF, diámetro Ferret; IR, índice de redondez; IA, índice de alargamiento.

\begin{tabular}{|c|c|c|c|c|c|c|c|c|c|c|c|c|}
\hline $\begin{array}{l}\text { Colectas y nivel } \\
\text { de germinación }\end{array}$ & $\begin{array}{c}\text { PS } \\
(\mathrm{mm})\end{array}$ & $\begin{array}{c}\mathrm{AS} \\
\left(\mathrm{mm}^{2}\right)\end{array}$ & $\begin{array}{c}\mathrm{PE} \\
(\mathrm{mm})\end{array}$ & $\begin{array}{c}\mathrm{AE} \\
\left(\mathrm{mm}^{2}\right)\end{array}$ & $\begin{array}{c}\text { GCS } \\
(\mathrm{mm})\end{array}$ & $\begin{array}{l}\text { LEHR } \\
(\mathrm{mm})\end{array}$ & $\mathrm{AE} / \mathrm{AS}$ & $\mathrm{AS} / \mathrm{AE}$ & $\mathrm{CE}\left({ }^{\circ}\right)$ & DF & IR & IA \\
\hline \multicolumn{13}{|l|}{ Germinación alta } \\
\hline Acaponeta, Nay. & $7.8 \pm 0.6$ & $4.0 \pm 0.7$ & $7.1 \pm 1.1$ & $0.97 \pm 0.21$ & $0.14 \pm 0.02$ & $2.43 \pm 0.27$ & $0.24 \pm 0.05$ & $4.26 \pm 0.82$ & $265 \pm 65.48$ & $2.26 \pm 0.18$ & $0.82 \pm 0.06$ & $1.13 \pm 0.09$ \\
\hline Tuxpan, Ver. & $8.2 \pm 0.4$ & $4.8 \pm 0.5$ & $9.1 \pm 1.2$ & $1.35 \pm 0.25$ & $0.15 \pm 0.02$ & $2.58 \pm 0.42$ & $0.28 \pm 0.04$ & $3.66 \pm 0.53$ & $322 \pm 22.4$ & $2.48 \pm 0.12$ & $0.90 \pm 0.01$ & $1.16 \pm 0.11$ \\
\hline \multicolumn{13}{|l|}{ Germinación media } \\
\hline Arizona M2, E.U.A. & $6.4 \pm 0.3$ & $3.0 \pm 0.3$ & $6.9 \pm 0.5$ & $0.72 \pm 0.08$ & $0.14 \pm 0.05$ & $2.07 \pm 0.36$ & $0.24 \pm 0.02$ & $4.13 \pm 0.36$ & $309 \pm 56.16$ & $1.94 \pm 0.08$ & $0.90 \pm 0.03$ & $1.22 \pm 0.14$ \\
\hline Cuetzalan, Pue. & $8.1 \pm 0.7$ & $4.6 \pm 0.7$ & $8.6 \pm 0.9$ & $1.19 \pm 0.13$ & $0.14 \pm 0.01$ & $2.47 \pm 0.38$ & $0.26 \pm 0.05$ & $3.93 \pm 0.74$ & $305 \pm 26.87$ & $2.42 \pm 0.18$ & $0.89 \pm 0.04$ & $1.14 \pm 0.09$ \\
\hline \multicolumn{13}{|l|}{ Germinación baja } \\
\hline Babiácora, Son. & $8.2 \pm 0.4$ & $4.8 \pm 0.5$ & $10.6 \pm 1.2$ & $1.34 \pm 0.19$ & $0.15 \pm 0.03$ & $3.03 \pm 0.21$ & $0.28 \pm 0.03$ & $3.60 \pm 0.44$ & $380 \pm 68.64$ & $2.46 \pm 0.12$ & $0.90 \pm 0.03$ & $1.20 \pm 0.08$ \\
\hline Badiraguato, Sin. & $6.3 \pm 0.2$ & $2.9 \pm 0.3$ & $7.7 \pm 0.9$ & $0.81 \pm 0.09$ & $0.12 \pm 0.01$ & $2.25 \pm 0.25$ & $0.28 \pm 0.02$ & $3.58 \pm 0.30$ & $392 \pm 61.00$ & $1.91 \pm 0.09$ & $0.91 \pm 0.04$ & $1.20 \pm 0.10$ \\
\hline Tomatlán, Jal. & $8.1 \pm 0.2$ & $4.7 \pm 0.2$ & $10 \pm 1.2$ & $1.24 \pm 0.15$ & $0.16 \pm 0.02$ & $2.66 \pm 0.37$ & $0.26 \pm 0.03$ & $3.87 \pm 0.43$ & $428 \pm 61.64$ & $2.45 \pm 0.05$ & $0.90 \pm 0.02$ & $1.13 \pm 0.06$ \\
\hline $\begin{array}{l}\text { La Montosa } \\
\text { Moctezuma, Son. }\end{array}$ & $6.6 \pm 0.4$ & $3.1 \pm 0.3$ & $7.7 \pm 0.8$ & $0.79 \pm 0.10$ & $0.13 \pm 0.01$ & $2.33 \pm 0.31$ & $0.25 \pm 0.03$ & $4.00 \pm 0.59$ & $382 \pm 77.62$ & $1.99 \pm 0.10$ & $0.89 \pm 0.02$ & $1.27 \pm 0.13$ \\
\hline Soto La Marina, Tam. & $7.5 \pm 0.3$ & $4.1 \pm 0.2$ & $8.5 \pm 0.7$ & $1.03 \pm 0.08$ & $0.15 \pm 0.02$ & $2.43 \pm 0.25$ & $0.25 \pm 0.02$ & $3.99 \pm 0.32$ & $352 \pm 56.46$ & $2.28 \pm 0.06$ & $0.92 \pm 0.03$ & $1.15 \pm 0.10$ \\
\hline Tepic, Nay. & $5.8 \pm 0.4$ & $2.5 \pm 0.3$ & $6.3 \pm 0.5$ & $0.66 \pm 0.08$ & $0.12 \pm 0.01$ & $1.79 \pm 0.22$ & $0.27 \pm 0.02$ & $3.72 \pm 0.35$ & $303 \pm 13.91$ & $1.76 \pm 0.11$ & $0.91 \pm 0.04$ & $1.21 \pm 0.13$ \\
\hline
\end{tabular}



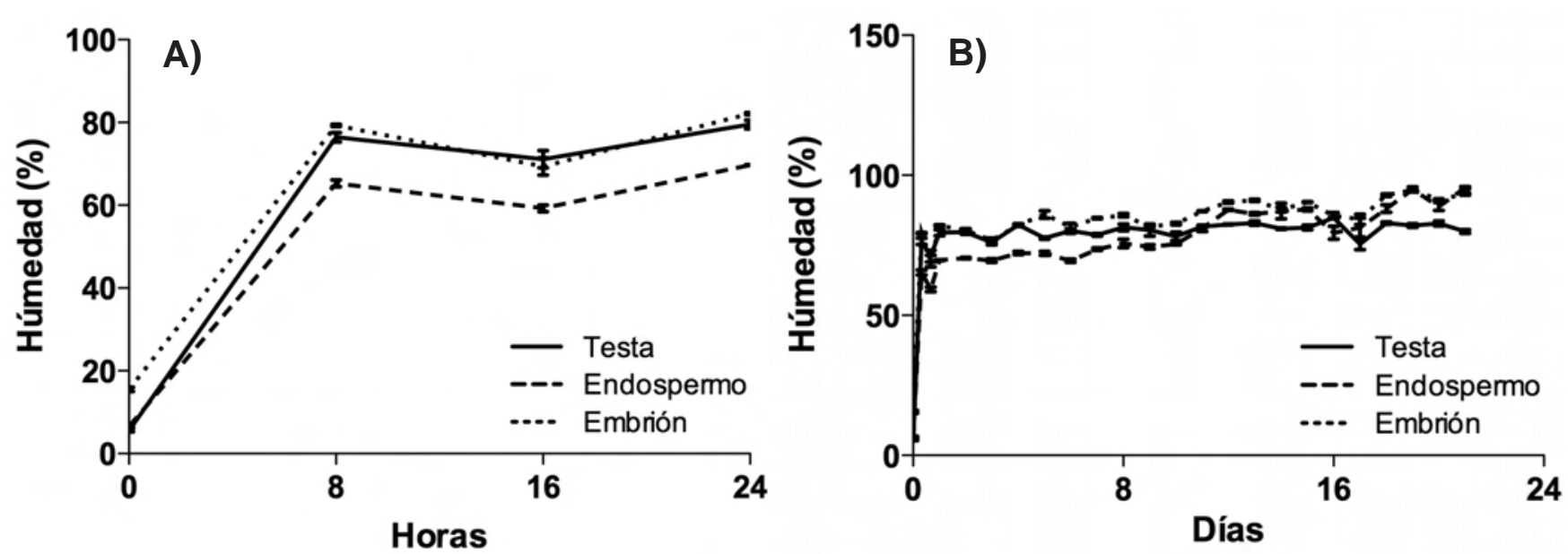

Figura 3. Cinética de imbibición durante la germinación de semillas de chile piquín provenientes de Tuxpan, Veracruz. A) Durante las primeras 24 h; B) Durante 21 días.

con película plástica y se colocaron en oscuridad en una incubadora Thelco® a temperatura constante de $30^{\circ} \mathrm{C}$.

La unidad experimental se conformó de diez semillas, con tres repeticiones por tratamiento. El número de semillas germinadas de cada caja se registró diariamente por 21 días. Transcurrido ese tiempo, se midió el peso fresco de las plántulas de cada muestra en una balanza analítica Sartorius H51. Después se secaron en estufa a $65{ }^{\circ} \mathrm{C}$ por $48 \mathrm{~h}$ y se determinó el peso seco.

\section{Resultados}

Variables morfológicas. Las colectas evaluadas mostraron diferencias significativas en el tamaño de la semilla, que es directamente proporcional al tamaño de su embrión (Cuadro 2). Los resultados evidenciaron que el nivel de germinación de las colectas no está relacionado con su tamaño, su forma, ni su lugar de origen. El grosor de la cubierta seminal no varía entre colectas. La longitud del eje del hipocótilo radicular no confiere mayor respuesta germinativa. En general, el embrión ocupa la cuarta parte del área total de la semilla de todas las colectas. Las semillas analizadas son casi redondas y la curvatura de los cotiledones permite que el embrión se acomode bien a pesar de que el perímetro del embrión es casi igual al perímetro de la semilla.

Cinéticas de imbibición y de distribución de biomasa. La cinética de imbibición permitió evaluar si la causa de baja germinación era causada por un impedimento físico que restringiera el paso de agua al interior de la semilla. Se encontró que el peso húmedo de la semilla alcanzó su máximo a las 8 h de imbibición en la colecta Tuxpan (Figura 3A). El contenido de humedad promedio previo a la germinación difirió entre los tejidos de la semilla de chile piquín, con $5.6 \%$ en la cubierta seminal, $6.6 \%$ en el endospermo y $15.6 \%$ en el embrión. Durante las primeras 8 h de imbibición, el contenido de humedad se elevó a $70 \%$ en la cubierta seminal, a $60 \%$ en el endospermo y a $76 \%$ en el embrión.

Por su parte, la cinética de distribución de biomasa mostró que la del endospermo disminuyó a lo largo de los 21 días de muestreos; mientras que la del eje embrionario, transformado en hipocótilo, aumentó progresivamente, lo que evidencia la redistribución de biomasa entre tejidos de reserva y el eje embrionario (Figura 4). En contraste, la cubierta seminal no modificó su peso a lo largo del experimento, comportamiento esperado debido a que dicha cubierta no aporta ni recibe biomasa durante la germinación. El peso promedio inicial del endospermo era de $5 \mathrm{mg}$, pero a los 21 días disminuyó a $1 \mathrm{mg}$; en el mismo intervalo, el peso promedio inicial del embrión aumentó de 1 a 4 mg.

Promotores de germinación. Después de haber demostrado que la limitante de germinación no consiste de una barrera física a la absorción del agua; y que por tanto, las bajas tasas

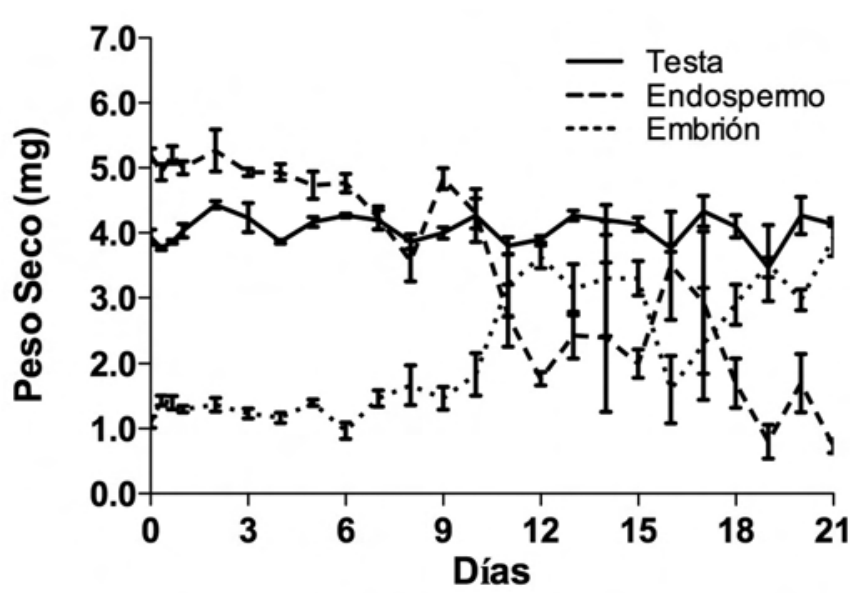

Figura 4. Cinética de distribución de biomasa entre la cubierta seminal, endospermo y embrión, durante 21 días de germinación de semillas de chile piquín procedentes de Tuxpan, Veracruz. 
Anaid CANo-VÁzQuez eT AL.

Cuadro 3. Análisis de varianza para germinación de semillas registrada en tres fechas (7, 14 y 21 días), de 16 colectas de chile piquín.

\begin{tabular}{|c|c|c|c|c|c|}
\hline Fuente de variación & Grados de libertad & Suma de cuadrados & Cuadrados medios & Valor de F & $\operatorname{Pr}>\mathrm{F}$ \\
\hline \multicolumn{6}{|c|}{$7 \mathrm{~d}$} \\
\hline Modelo & 63 & 4.62 & 0.07 & 18.5 & 0.0001 \\
\hline Promotores $(\mathrm{P})$ & 3 & 0.14 & 0.05 & 12.1 & 0.0001 \\
\hline Colectas (C) & 15 & 3.37 & 0.22 & 56.8 & 0.0001 \\
\hline $\mathrm{C} \times \mathrm{P}$ & 45 & 1.10 & 0.02 & 6.2 & 0.0001 \\
\hline \multicolumn{6}{|c|}{$14 \mathrm{~d}$} \\
\hline Modelo & 63 & 13.94 & 0.22 & 13.8 & \\
\hline Promotores $(\mathrm{P})$ & 3 & 2.10 & 0.70 & 43.8 & 0.0001 \\
\hline Colectas (C) & 15 & 9.77 & 0.65 & 40.7 & 0.0001 \\
\hline $\mathrm{C} \times \mathrm{P}$ & 45 & 2.06 & 0.05 & 2.9 & 0.0001 \\
\hline \multicolumn{6}{|c|}{$21 \mathrm{~d}$} \\
\hline Modelo & 63 & 18.42 & 0.29 & 17.3 & 0.0001 \\
\hline Promotores $(\mathrm{P})$ & 3 & 5.02 & 1.67 & 99.1 & 0.0001 \\
\hline Colectas (C) & 15 & 10.45 & 0.70 & 41.3 & 0.0001 \\
\hline $\mathrm{C} \times \mathrm{P}$ & 45 & 2.95 & 0.06 & 3.9 & 0.0001 \\
\hline
\end{tabular}

de germinación del chile piquín son atribuibles a latencia de la semilla, se evaluaron tres promotores de germinación: $\mathrm{AG}_{3}, \mathrm{KNO}_{3} \mathrm{y} \mathrm{H}_{2} \mathrm{O}_{2}$.

Los datos de germinación registrados a los 7, 14 y 21 días, en las 16 colectas de chile piquín pretratadas con promotores de la germinación (Cuadro 3), evidenciaron que en las tres fechas hubo diferencias significativas $(P$ $\leq 0.0001)$ entre colectas y entre promotores, así como en la interacción "promotores $\times$ colectas", efectos que representaron las siguientes proporciones de la variación total debida a tratamientos: $55 \%$ por efecto de colectas, $28 \%$ por efecto de promotores, y $17 \%$ debido a la interacción; lo cual evidencia que las principales fuentes de variación fueron las colectas y los promotores.

En promedio, de las 16 colectas, el tratamiento de acondicionamiento que más promovió la germinación fue el de ácido giberélico, ya que los tratamientos con nitrato de pota-

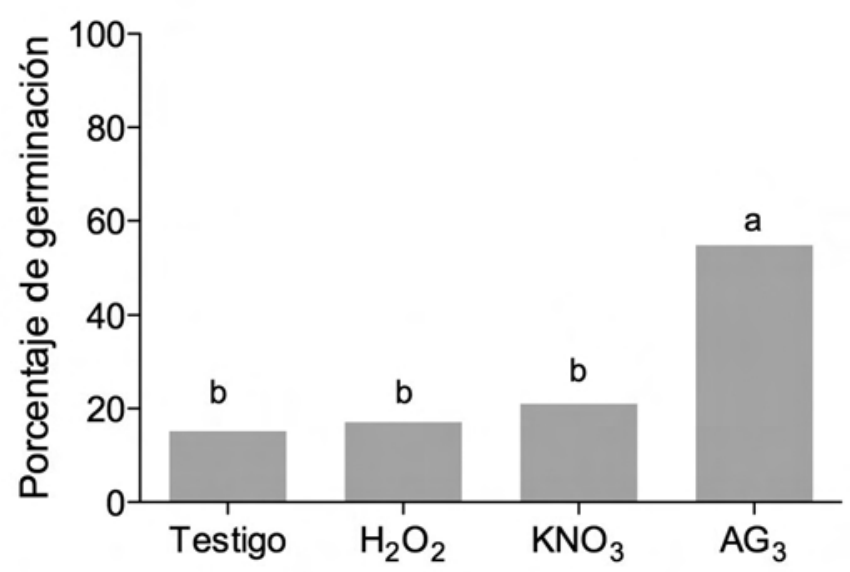

Figura 5. Efecto de promotores de germinación aplicados a semillas de chile piquín. Promedio de 16 colectas. sio y peróxido de hidrógeno no modificaron el porcentaje de germinación en comparación con el testigo sin promotores (Figura 5).

Entre colectas hubo una amplia variación, ya que mientras las semillas provenientes de Acaponeta y Tuxpan alcanzaron tasas de germinación mayores de $70 \%$, el promedio de tratamientos de promotores, en las tasas de las semillas de La Montosa, Soto La Marina, Arizona M1, La Montosa Moctezuma, Sonora, Tepic y Xicotepec, fueron menores de $20 \%$ (Figura 6). También se registraron diferencias significativas $(P \leq 0.001)$ en las respuestas a los tratamientos de acondicionamiento. Aunque en la mayoría de las colectas el peróxido de hidrógeno y el nitrato de potasio tuvieron un comportamiento similar al testigo sin aplicación de un tratamiento promotor (Figura 7A, B).

El nitrato de potasio tuvo un escaso efecto promotor de la germinación y muy variable entre las colectas de chile piquín (Figura 7B). Aunque a los 35 días de la germinación, el tratamiento de nitrato de potasio tuvo el mismo resultado que el ácido giberélico.

El tratamiento de ácido giberélico tuvo un mayor efecto promotor de la germinación en la mayoría de las colectas de chile piquín (Figura 7C); excepto en las colectas Tepic y Xicotepec, las cuales mantuvieron porcentajes de germinación similares al testigo. Notablemente, las semillas de Babiácora incrementaron su germinación de cero a $90 \%$, y las de Badiraguato de 3 a $76 \%$.

Es importante resaltar que el tratamiento hormonal solo se aplicó durante las primeras 24 h de imbibición, porque en esta investigación se encontró que 24 h son suficientes para que la semilla alcance el máximo de absorción de agua, por lo que aquí se supuso que los tratamientos de acondicionamiento no requerían más de $24 \mathrm{~h}$ para penetrar la semilla. 


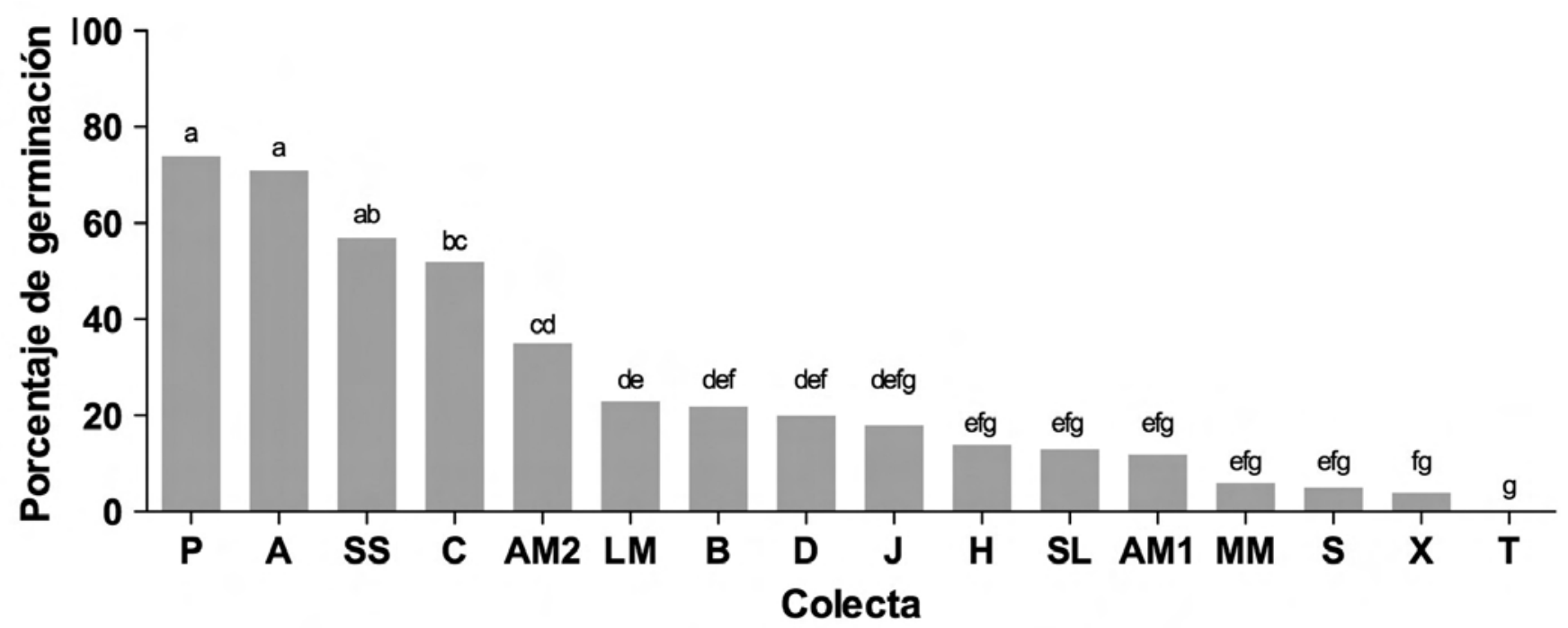

Figura 6. Germinación en agua, en promedio de 16 colectas de semillas de chile piquín. P, Tuxpan; A, Acaponeta; B, Babiácora; C, Cuetzalan; SS, Sierra de Sonora; D, Badiraguato; J, Tomatlán; AM2, Arizona M2; H, Huepac; LM, La Montosa; SL, Soto La Marina; AM1, Arizona M1; MM, La Montosa Moctezuma; S, Sonora; T, Tepic; X, Xicotepec.

\section{Discusión}

Variables morfológicas. Los datos morfológicos obtenidos de las fotografías evidenciaron que existe una relación directa entre el tamaño de la semilla y el tamaño del embrión (Cuadro 2), ya que a mayor área de semilla el área del embrión también es mayor. En cambio, los perímetros de la semilla y del embrión tienen valores similares, lo cual se atribuye a que el embrión se acomoda a lo largo de casi todo el endospermo. En cuanto al tamaño de la semilla, hubo diferencias entre colectas, resaltando la colecta Tepic, con la semilla más pequeña.

En los cocientes entre variables morfológicas, las colectas mostraron resultados similares (Cuadro 2). El grosor de la cubierta seminal es muy similar en todas las colectas, con 0.14 a $0.16 \mathrm{~mm}$, con excepción de las de Tepic, Badiraguato y La Montosa Moctezuma, que son las más delgadas (0.12 a $0.13 \mathrm{~mm}$ ), así como de menor tamaño. La colecta Babiácora sobresale de otras colectas en la longitud del eje hipocótiloradícula, aunque esto no representa ventajas en la germinación, como se muestra posteriormente. La proporción entre las áreas del embrión y de la semilla también resultó similar en todas las colectas, lo que indica que el embrión ocupa en promedio $26 \%$ del tamaño de la semilla, o que la semilla es cuatro veces mayor que el embrión.

En todas las colectas, el embrión se enrolla y los cotiledones siguen el mismo acomodo. La curvatura del embrión es muy similar al encontrado en semillas de Opuntia spp. (Guerrero-Muñoz et al., 2006). Estos índices morfológicos muestran que las semillas de estas colectas de chile piquín están muy cerca de llegar a la redondez total, ya que su valor de alargamiento es muy bajo. El diámetro Ferret indica que las semillas tienen alto nivel de compactación. Los datos obtenidos no muestran una diferencia morfológica clara que permita distinguir una semilla con alta germinación de una de baja germinación.

Cinéticas de imbibición y distribución de biomasa. Según Taiz y Zeiger (2010), el proceso de germinación se activa una vez que se hidratan los tejidos de la semilla, lo que genera una cadena de eventos irreversibles. El proceso inicia con la degradación de azúcares en el endospermo, así como la importación de azúcares hacia el embrión para promover el crecimiento de este; asimismo se activan genes involucrados en la germinación.

Los porcentajes de humedad alcanzados en semillas de chile piquín de la colecta de Tuxpan, Veracruz, permiten inferir que la penetración de agua hacia el interior de la semilla no fue el factor limitante de la germinación (Figura 3B), y además que la hidratación ocurre en las primeras $8 \mathrm{~h}$ de la imbibición, en coincidencia con lo descrito por Dell'Aquila (2004) en semillas de chile (Capsicum annuum L.) y tomate (Lycopersicon esculentum L. = Solanum lycopersicum L.). Este comportamiento contrasta con el observado en semillas de maíz (Zea mays L.) por Cruz-Pérez et al. (2003), en las que el endospermo presenta lenta imbibición en las primeras $10 \mathrm{~h}$.

Estos resultados indican que el endospermo traslocó $3 \mathrm{mg}$ equivalentes de biomasa al embrión en crecimiento (protrusión de la radícula). La diferencia de peso $(1 \mathrm{mg})$ se puede explicar por el gasto necesario de energía (respiración) para mantener el metabolismo activo de la semilla. La aportación de reservas por el endospermo coincide con la reportada por Anese et al. (2011) en semillas de Solanum lycocarpum, quien relacionó el desgaste del endospermo durante la germinación. 

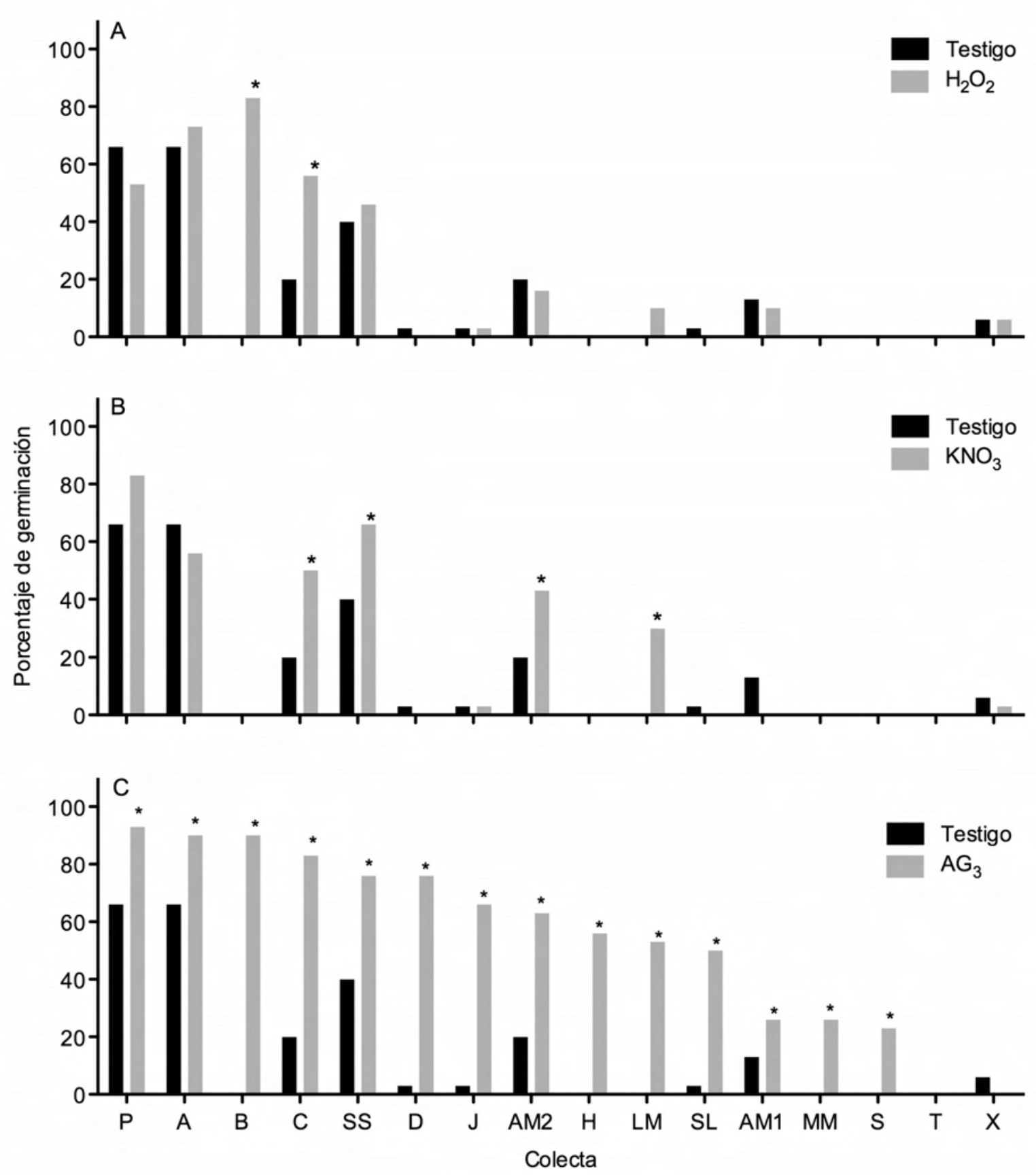

Figura 7. Efecto de tratamiento de semillas de chile piquín con: A) peróxido de hidrógeno, B) nitrato de potasio y C) ácido giberélico, en la germinación de 16 colectas. Las barras negras corresponden al testigo, las barras grises al tratamiento. El asterisco indica diferencia significativa entre el testigo y el tratamiento. P, Tuxpan; A, Acaponeta; B, Babiácora; C, Cuetzalan; SS, Sierra de Sonora; D, Badiraguato; J, Tomatlán; AM2, Arizona M2; H, Huepac; LM, La Montosa; SL, Soto La Marina; AM1, Arizona M1; MM, La Montosa Moctezuma; S, Sonora; T, Tepic; X, Xicotepec.

Promotores de germinación. Con la aplicación de peróxido de hidrógeno, cinco colectas alcanzaron valores de 40 a $80 \%$ de germinación (Figura 7A), de las cuales cuatro (Acaponeta, Cuetzalan, Sierra Sonora y Tuxpan), empezaron a germinar desde el día 5, y Babiácora empezó hasta el día 15. Otras cuatro colectas (Arizona M1, Tomatlán, Xicotepec y La Montosa) germinaron, pero con valores bajos de 3 a 14\%, y algunas colectas no germinaron en absoluto (Badiraguato, Huepac, La Montosa Moctezuma, Soto La Marina y Tepic). Yadav et al. (2011) aumentaron la germinación de semillas de Capsicum annuum del cv. California Wonder con $\mathrm{H}_{2} \mathrm{O}_{2}$, en comparación con el testigo. Es decir, el efecto del $\mathrm{H}_{2} \mathrm{O}_{2}$ fue bueno en colectas de mediana germinación, pero pobre en colectas de baja germinación. 
El $\mathrm{KNO}_{3}$ tuvo un efecto de menor magnitud, y más variable que el $\mathrm{H}_{2} \mathrm{O}_{2}$ en la germinación de las semillas de chile piquín (Figura 7B), al igual que en otras especies. Cuando se aplicó $\mathrm{KNO}_{3}$ a semillas de papayo (Carica papaya) no hubo diferencia significativa entre este y el testigo, con respecto a la germinación (Andrade-Rodríguez et al., 2008). Por otro lado, el $\mathrm{KNO}_{3}$ también puede inhibir la germinación, como en la cebolla (Allium cepa L.) cv. Early Supreme, en la que este tratamiento redujo la germinación de 82 a $73 \%$ y no presentó ventaja en uniformidad de emergencia (Marín et al., 2007; Guo et al., 2012). En otras especies, como en Ischaemum rugosum, el uso de $\mathrm{KNO}_{3}$ logró mejorar la germinación de 20 a $96 \%$ (Jarma et al., 2007) y, en Pinus bungeana la germinación aumentó de 13.3 a $43.3 \%$ con respecto al testigo. En Vaccinium meridionale, el $\mathrm{KNO}_{3}$ no tuvo diferencia contra el testigo sino hasta los 35 días después de la siembra, cuando alcanzó $50 \%$ de germinación contra 38\% del testigo (Magnitskiy y Ligarreto, 2007).

El ácido giberélico incrementó el porcentaje de germinación en mayor magnitud en la mayoría de las colectas (Figura 7C). Estos resultados muestran dos aspectos fundamentales de la promoción de la germinación en semillas de chile piquín: (1) que el ácido giberélico puede ser utilizado a concentraciones altas en chile piquín sin ser tóxico a la semilla y, (2) que la aplicación de ácido giberélico como tratamiento hormonal promueve significativamente la germinación de la mayoría de colectas.

El efecto promotor del ácido giberélico, en altas concentraciones, sobre la germinación de semillas de esta especie, también ha sido reportado por otros investigadores. Así, en colectas de chile piquín de Tamaulipas, Ramírez (2008) logró incrementar el porcentaje de germinación de 1 a 75\% con 5,000 ppm de ácido giberélico. Con el mismo tratamiento, García et al. (2004) incrementaron de 33 a $82 \%$ la germinación en colectas de chile piquín provenientes de dos localidades de Querétaro. También coinciden con los obtenidos en semillas de papaya (Carica papaya L.) tratadas con 346 ppm de ácido giberélico (Andrade-Rodríguez et al., 2008), y de chile piquín tratadas con ácido giberélico a 400 ppm durante 20 h (Araiza et al., 2011). En cambio, contrasta con la obtenida en Nicotiana benthamiana, cuyas semillas latentes no mejoraron el porcentaje de germinación mediante la aplicación exógena de esta hormona a 34 ppm (Wünschová et al., 2009).

La germinación de una semilla es un evento complejo, regulado por una variedad de genes y eventos fisiológicos que son difíciles de separar (Koornneef et al., 2002). Sin embargo, no es extraño observar que una fitohormona modifique tan radicalmente la germinación (Richards et al., 2001). En este estudio se puede postular que las colectas de chile piquín varían ampliamente en el grado de germinación de la semilla, lo que evidencia diversos grados de latencia. Esta variabilidad se puede aprovechar para la domesticación y mejoramiento genético de la especie. También se demuestra que la fitohormona $\mathrm{AG}_{3}$ es capaz de romper la latencia de la mayoría de colectas, pero en magnitudes variables entre colectas.

\section{Conclusiones}

En 16 colectas de chile piquín (Capsicum annuum var. glabriusculum) no se observaron diferencias morfológicas claras, asociadas con sus tasas de germinación en las colectas evaluadas. En la mayoría de las colectas, las semillas tienen la misma forma y morfología, con excepción de las colectas de Tepic y Badiraguato, cuyas semillas son más pequeñas. $\mathrm{Ni}$ la cubierta seminal ni el endospermo fueron limitantes para impedir el paso de agua al interior de la semilla, ya que bastaron $8 \mathrm{~h}$ para alcanzar el máximo de absorción de agua por la semilla. El tratamiento de preacondicionamiento que promovió la germinación en semillas de chile piquín, en la mayoría de colectas, fue el de ácido giberélico aplicado a 5,000 ppm; solamente las colectas Tepic y Xicotepec no mejoraron su germinación con $\mathrm{AG}_{3}$.

\section{Agradecimientos}

Nuestro mayor agradecimiento a los tres revisores y un editor anónimos, cuyo minucioso trabajo nos permitió detectar los errores involuntarios, así como mejorar la redacción y estructura del presente manuscrito. Estas revisiones confirman la importancia del arbitraje en las publicaciones científicas, además de ser un valioso apoyo a los autores.

\section{Literatura citada}

Andrade-Rodríguez M., Ayala-Hernández J.J., Alia-Tejacal I., Rodríguez-Mendoza H., Acosta-Durán C.M. y López-Martínez V. 2008. Efecto de promotores de la germinación y sustratos en el desarrollo de plántulas de papayo. Revista de la Facultad de Agronomía. 25:617-635.

Anese S, da Silva E.A.A., Davide A.C., Rocha F.J.M., Soares G.C.M., Matos A.C.B., y Toorop P.E. 2011. Seed priming improves endosperm weakening, germination, and subsequent seedling development of Solanum lycocarpum St. Hil. Seed Science and Technology 39:125-139.

Araiza L.N., Araiza L.E., Martínez M.J.G. 2011. Evaluación de la germinación y crecimiento de plántula de chiltepín (Capsicum annuит L. variedad glabriusculum) en invernadero. Revista Colombiana de Biotecnología 13:170-175.

Bañuelos N, Salido P.L., Gardea A. 2008. Etnobotánica del chiltepín. Pequeño gran señor en la cultura de los sonorenses. Estudios Sociales (Hermosillo, Son.) 16:177-205.

Cano-Vázquez A. 2013. Germinación en semilla de chile piquín (Capsicum annuum var. aviculare). Tesis de Maestría en Recursos Genéticos y Productividad, Postgrado en Recursos Genéticos y Productividad, Colegio de Postgraduados, Campus Montecillo. 7980 pp.

Chen F. y Bradford K.J. 2000. Expression of an expansin is associated with endosperm weakening during tomato seed germination. Plant Physiology 124:1265-1274. 
Cruz-Pérez A.B., González-Hernández V.A., Mendoza-Castillo M.C., Ortega-Delgado M.L. 2003. Marcadores fisiológicos de la tolerancia al envejecimiento de semilla en maíz. Agrociencia 37:371-381.

Dell' Aquila A. 2004. Cabbage, lentil, pepper and tomato seed germination monitored by an image analysis system. Seed Science and Technology 32:225-229.

Flores G.A., Álvarez M.J.G., Rodríguez de la O J.L. y Corona A.A. 2008. Germinación in vitro de semillas de Nolina parviflora (H.B.K.) Hemsl. Foresta Veracruzana 10:27-33.

García F.A., Montes H.S. y Rangel L.J.A. 2004. Calidad fisiológica de la semilla de chile piquín (Capsicum annuum var. aviculare) en dos localidades de Querétaro. Memorias de la Primera convención mundial del chile, 27-29 junio León, pp: 49-53, Guanajuato.

García F.A., Montes H.S., Rangel L.J.A., García M.E. y Mendoza E.M. 2010. Respuesta fisiológica de la semilla chile piquín (Capsicum annuum var. glabriusculum (Dunal) Heiser \& Pickersgill) al ácido giberélico e hidrotermia. Revista Mexicana de Ciencias Agrícolas 1:203-216.

Guerrero-Muñoz P., Zavaleta-Mancera H.A., Barrientos-Priego A.F., Gallegos-Vázquez C., Núñez-Colín C.A., Valadez-Moctezuma E. y Cuevas-Sánchez J.A. 2006. Técnica para el estudio de la micromorfología interna de semillas duras en Opuntia. Revista Fitotecnia Mexicana 29 (Núm. Esp. 2):37-43.

Guo S.J., Wang Y.C., Wang W.S. 2012. Effects of priming treatments on germination and biochemical characteristics of Pinus bungeana seeds. Forestry Studies in China 14:200-204.

Hernández-Verdugo S., López-España R.G., Porras F., Parra-Terraza S. T., Villarreal-Romero M. y Osuna-Enciso T. 2010. Variación en la germinación entre poblaciones y plantas de chile silvestre. Agrociencia 44:667-677.

Jarma A.J., Arbelaez J.C. y Clavijo J. 2007. Germinación de Ischaemum rugosum Salisb. en respuesta a estímulos ambientales y químicos. Temas Agrarios 12:31-41.

Koornneef M., Bentsink L., y Hilhorst H. 2002. Seed dormancy and germination. Current Opinion in Plant Biology 5:33-36.

López-Santiago J., Nieto-Ángel R., Barrientos-Priego A.F., Rodríguez-Pérez E., Colinas-Leon M.T., Borys M.W. y GonzálezAndrés F. 2008. Selección de variables morfológicas para la caracterización del tejocote (Crataegus spp.). Revista Chapingo, Serie Horticultura 14:97-111.

Magnitskiy S.V. y Ligarreto G.A. 2007. El efecto del nitrato de potasio, del ácido giberélico y del ácido indolacético sobre la germinación de semillas de agraz (Vaccinium meridionale Swartz).
Revista Colombiana de Ciencias Hortícolas 1:137-141.

Marín S.J., Mejía C.J.A, Hernández L.A., Carballo C.A. y Peña L.A. 2007. Acondicionamiento osmótico de semillas de cebolla (Allium cepa L.). Agricultura Técnica en México 33:63-71.

Medina-Martínez T., Rodríguez del Bosque L.A., Villalón-Mendoza H., Pozo-Campodónico O., Ramírez-Meraz M., López de León R., Lara-Villalón M., Gaona-García G., Cardona-Estrada A. y Mora-Olivo A. 2002. El chile piquín (Capsicum annuum var. aviculare) en el noreste de México. Aspectos ecológicos y socioeconómicos. Revista BIOTAM n.s.13:1-14.

Medina-Martínez T., Villalón-Mendoza H., Pérez-Hernández J.M., Sánchez R.G. y Salinas-Hernández S. 2010. Avances y perspectivas de investigación del chile piquín en Tamaulipas, México. Ciencia UAT 4:16-21.

Núñez-Colín C.A., Serrato-Cruz M.A, Santos-Cortés M.T., LunaMorales C.C., Martínez-Solís J. y Cuevas-Sánchez J.A. 2011 Caracterización de Tagetes filifolia del centro-sur de México por morfometría de los aquenios. Revista Mexicana de Biodiversidad 82:539-549.

Ogawa K. e Iwabuchi M. 2001. A mechanism for promoting the germination of Zinnia elegans seeds by hydrogen peroxide. Plant and Cell Physiology 42:286-291.

Ramírez M.M. 2008. Chile piquín. 1. Tecnología para incrementar germinación y conservar especies silvestres de chile piquín. Ficha Tecnológica por Sistema Producto. Secretaría de Agricultura, Desarrollo Rural, Pesca y Alimentación, Instituto Nacional de Investigaciones Forestales, Agrícolas y Pecuarias. <http:// biblioteca.inifap.gob.mx:8080/xmlui/handle/123456789/1001> (consultado agosto 2013)

Richards D.E., King K.E., Ait-ali T., y Harberd N.P. 2001. How gibberellin regulates plant growth and development: A molecular genetic analysis of gibberellin signaling. Annual Review Plant Physiology and Plant Molecular Biology 52:67-88.

Shim S.I., Moon J.C., Jang C.S., Raymer P. y Kim W. 2008. Effect of potassium nitrate priming on seed germination of seashore paspalum. HortScience 43:2259-2262.

Taiz L. y Zeiger E. 2010. Plant Physiology. 5th ed. Sinauer Associates, Inc., Sunderland,

Wünschová A., Beňová V., Vlašínová H. y Havel L. 2009. Dormancy of Nicotiana benthamiana seeds can be broken by different compounds. Biologia Section Botany 64:705-710.

Yadav P.V., Kumari M. y Ahmed Z. 2011. Seed priming mediated germination improvement and tolerance to subsequent exposure to cold and salt stress in Capsicum. Research Journal of Seed Science 4:125-136.

Recibido: 19 de septiembre de 2013

Aceptado: 15 de enero de 2014. 